\title{
Communist party of China building science level: the new era party's new mission
}

\author{
Jiajue FANG $^{1, a}$, Chunxia JIANG ${ }^{2, b, ~ * ~}$ \\ ${ }^{1}$ Guangxi Science \& Technology Normal University, Laibin, Guangxi, PRC \\ 2 Guilin University Of Aerospace Technology, Guilin, Guangxi, PRC \\ ajiayu10000@163.com, b18777396217@163.com \\ ${ }^{*}$ Corresponding author
}

Key words: New Times ; Communist party of China building ；Scientific level

\begin{abstract}
Improving the scientific level of the party's construction is an important and major issue of the new era. The connotation and essence of it is to be grasped correctly under the new era. With the time of the achievement and the summary of historical experience, we follow the law and prom ote the party construction scientifically; The root is grasped and the whole party with the socialist ideology with Chinese characteristics is armed in Xi jinping's new era; The soul of the nation is builded and the party's leadership of all is firmed; The new mission of the new century is fulfilled around the centre; Party discipline will be comprehensively strict into the depth; Breaking into the new era of a central issue for "what kind of party and how to build the party will be" walks into the new journey.
\end{abstract}

\author{
党的建设科学化：新时代党的建设新使命 \\ 方家珏 ${ }^{1, a}$, 蒋春霞 $2, \mathrm{~b},{ }^{\star}$ \\ 1广西科技师范学院教务处, 来宾, 广西, 中国 \\ 2桂林航天工业学院校长办公室, 桂林, 广西, 中国 \\ a jiayu10000@163.com, b18777396217@163.com \\ “通讯作者
}

关键词: 新时代; 党的建设; 科学化水平

摘要: 提高党的建设科学化水平是新时代的重大课题和党的建设重要问题。正确把握新时代 下党的建设科学化的内涵和本质, 在时代成就追逼和总结历史经验条件下, 遵循规律, 全面 推进党的建设科学化; 抓住根本, 用习近平新时代中国特色社会主义思想武装全党; 筑牢国 魂, 坚定党对一切的领导; 围绕中心, 履行新世纪新阶段新使命; 注重实效, 全面从严治党 向纵深发展，破解新时代 “建设什么样的党、如何建设党” 的中心问题进入新征程。

\section{1. 新时代何谓? 党建科学化何谓?}

\section{1 新时代}

所谓新时代是从党的十八大开启的，是以习近平同志为核心的党中央的坚强领导的，是 全面建设小康社会不断实现中华民族伟大复兴的中国梦的时代。历史卓著的成就带领我们走 
进了新时代, 这五年是以习近平同志为核心的党中央举旗定向、力挽狂澜, 淬火成钢、攻坚 克难, 砥研奋进、成就辉煌的五年; 这五年是党、国家和军队凤凰涅槃、浴火重生, 更强大、 更有力量的五年; 这五年是中国经济发展、政治稳定、社会安定、人民幸福、百业兴盛的五 年, 这五年是党和国家发展进程中极不平凡的五年。“五年来的成就是全方位的、开创性的, 五年来的变革是深层次的、根本性的。”（十九大报告）五年的时间, 带领我们走进中国特 色社会主义新时代。

\section{2 新时代的内涵}

\section{2 .1 新时代是日益走进世界舞台中央的时代}

“中国特色社会主义进人新时代” 是对世情、国情、党情深人分析和准确判断基础上得 出的科学结论。中国特色社会主义由站起来、富起来到强起来, 由屹立于世界民族之林到日 益走进世界舞台中央的时代。从中国社会经济发展进程来看, 经过新中国成立以来近 70 年尤 其是改革开放以来近 40 年的发展和建设, 我国经济社会发展取得了巨大成就, 创造了发展的 奇迹, 中国特色社会主义事业稳步向前推进。在中国高速经济发展物质文化丰富, 实现中华 民族伟大复兴的中国梦的同时, 以中国梦联系支撑世界各国人民的梦想, 重点通过 “一带一 路” 高举和平发展的旗帜, 积极发展与沿线国家的经济合作伙伴关系, 共同打造政治互信、 经济融合、文化包容的利益共同体、命运共同体和责任共同体。中国 1 共产党作为一个负责 人的大党, 建设中国理念、中国方案、中国行动足以证明要让世界远离恐惧、普遍安全、更 加美好坚定决心, 让人人享有安宁祥和世界, 让人人享有富足安康生活, 让各种文明和谐共 存，让人人享有文化滋养的开放包容的天下。

\section{2 .2 新时代是新矛盾新要求的时代}

党的十八大以来，以习近平同志为核心的党中央带领全党谋篇布局，举旗定向，开拓了 中国特色社会主义发展新境界, 党和国家事业发生了历史性变革, 这些变革体现在经济、政 治、文化、社会、生态、党的建设等各个领域, 中国特色社会主义表现出了新的阶段性特征。 中国特色社会主义发展有着鲜明的阶段性特征, 这是由不同历史时期的主要矛盾、主要任务 的不同所决定的。在党的十九大报告中, 习近平同志特别指出我国社会主要矛盾已经转化为 “人民日益增长的美好生活需要和不平衡不充分的发展之间的矛盾; 这是一个关系全局的历 史性变化。针对社会主要矛盾的发展变化, 坚持问题导向, 致力于解决现实生活中和群众思 想上迫切需要解决的问题, 就要 “牢牢把握我国发展的阶段性特征, 牢牢把握人民群众对美 好生活的向往” 提出新的思路、新的战略、新的举措, 不断推进中国特色社会主义事业沿着 正确的方向发展。习近平同志特别强调要重视形势分析, 目的是要 “使全党同志特别是各级 领导干部增强忧患意识, 做到居安思危、知危图安”。当前, 处在全面建成小康社会的决胜 阶段, 各方面各领域的任务仍很艰巨, 党和国家的事业仍面临各种风险和挑战, 这也对全党 提出了新的更高的要求。

\section{2 .3 新时代新思想新领航的时代}

时代是思想之母, 实践是理论之源。新的时代和新的实践需要新的思想理论, 也必将孕 育出新的思想理论一一习近平新时代中国特色社会主义思想。十九大提出, 习近平新时代中 国特色社会主义思想, 是对马克思列宁主义、毛泽东思想、邓小平理论、“三个代表” 重要 思想、科学发展观的继承和发展, 是马克思主义中国化最新成果, 是党和人民实践经验和集 体智慧的结晶, 是中国特色社会主义理论体系的重要组成部分, 是全党全国人民为实现中华 民族伟大复兴而奋斗的行动指南, 是对十八大以来我们党理论创新成果的最新概括和表述, 系统回答新时代坚持和发展什么样的中国特色社会主义、怎样坚持和发展中国特色社会主义 等重大问题。习近平新时代中国特色社会主义思想极大丰富和发展了马克思主义, 丰富和发 展了中国特色社会主义理论体系, 是马克思主义中国化的最新成果, 是新时代中国化的马克 思主义。习近平新时代中国特色社会主义思想, 开辟马克思主义国别化、时代化和大众化的 新境界, 赋予马克思主义科学社会主义理论新的活力和生命力, 以鲜明的中国特色、时代特 
征和大众特点载入马克思主义发展史册, 是新时代全党全国各族人民为实现中华民族伟大复 兴而奋斗的旗帜和行动指南, 是立足当代中国现实, 结合当今时代条件, 发展面向现代化、 面向世界、面向未来的, 民族的科学的大众的社会主义文化, 为新时代中国特色社会主义建 设提供了强大的精神动力和智力支持。凸显出新时代思想文化引领的极端重要性, 展示出新 时代思想文化的巨大活力, 需要我们坚持党的领导下不断提高党的建设科学化水平。

\section{3 党的建设科学化}

马克思恩格斯认为，共产党人同其他无产阶级政党不同的地方只是：“一方面，在无产 阶级不同的民族的斗争中，共产党人强调和坚持整个无产阶级共同的不分民族的利益; 另一方 面, 在无产阶级和资产阶级的斗争所经历的各个发展阶段上, 共产党人始终代表整个运动的 利益。因此, 在实践方面, 共产党人是各国工人政党中最坚决的、始终起推动作用的部分; 在理论方面, 他们胜过其余的无产阶级群众的地方在于他们了解无产阶级运动的条件、进程 和一般结果。” ${ }^{[1]}$ 也就是说, 共产党比其他工人政党更先进。这种先进性表现在两个方面, 即实践的先进件和理论的先进性。随着时代发展, 党的建设提出更高要求, 全面建设党的科 学化水平成为党的重大课题。那么, 什么叫做党的建设科学化? 党的建设科学化意味着什么? 那就是党的建设要从时代的角度, 与时俱进的角度重新认识。党的建设科学化就意味着我们 要从规律的角度去把握党的建设问题, 把党的建设放在系统的角度放在整体的角度去加以分 析研究提供解决问题的办法。所以说它无论是理论含量还是它的实践含量都是非常之广阔、 非常之深厚，因此非常值得我们去加以研究。

理论上 “没有革命的理论，就没有革命的运动”， ${ }^{[2]}$ 党的建设科学化水平的提出，在党 的文献中是第一次, 但是科学化要求的体现, 在党的建设中不是刚开始。实践上, 提高是在 原有水平上的提高, 是对原有水平的提高, 是总结历史经验提出的结论。党的建设科学化的 成长历程是在毛泽东时期。他针对红军第四军共产党内存在的单纯军事观点、极端民主化、 绝对平均主义等各种非无产阶级思想, 提出了党的建设科学化的主张, 强调要 “使党员的思 想和党内的生活都政治化, 科学化”。 ${ }^{[3]}$ 邓小平同志在改革开放之初提出, 党在领导社会主 义事业中, 要 “采取科学的态度”, “要有一套科学的办法”。 ${ }^{[4]}$ 他还强调, “为了坚持党 的领导, 必须努力改善党的领导” , [5] “除了改善党的组织状况以外, 还要改善党的领导工作 状况, 改善党的领导制度” ${ }^{[6]}$ 。强调用科学态度、科学办法坚持和改善党的领导, 正是要实 现党的领导和党的建设科学化。到江泽民时期, 1988 年要求各级党政领导, 要把 “领导工作 真正建立在科学的基础上”。他强调, 要 “加强学习, 扎实工作, 增加工作中的预见性和科 学性, 防止盲目性和片面性” [7]。2001 年, 他又强调, “我们搞社会主义现代化建设, 我们 的思想方法和思维方式也必须符合现代化建设的要求, 本身也应现代化。而思想方法和思维 方式的现代化, 也就是要按照科学精神来观察、思考和解决各种问题” ${ }^{[8]}$ 。他还强调, 要坚 持和完善能够保证党的领导坚强有力和社会主义兴旺发达的一整套 “科学的制度”。胡锦涛 强调党要 “以科学的思想、科学的制度、科学的方法领导中国特色社会主义事业”, “要把 树立和落实科学发展观与掌握科学的思想方法紧密结合起来”，“以科学态度抓好发展”， 坚持 “科学发展、和谐发展、和平发展”。祝倡导和推动党的建设科学化, 是我们党在革命、 建设、改革各个发展阶段一以贯之的自我追求。最后在十七届四中全会把党的建设作为一个 整体, 提出科学化问题, 确是第一次。随着时代的发展, 在习近平党的建设理论中明确指出 党的建设科学化需要有科学理论指导、科学制度保障、科学方法支撑, 这是科学化在具体实 施过程中的基本要求，也是科学化的应有之意。以此我们对对科学化有基本认识:

其一, 科学化是对规律的把握和遵循。科学化首先需要探索、把握和遵循规律, 按规律 办事。科学的本意就在于研究、揭示和认识规律, 每一门科学就是对特定领域规律的揭示, 党的建设科学化就是对党的建设这一规律的把握和遵循。党的建设科学化需要把握执政活动 的一般规律和中国共产党活动与规律以及市场经济规律。

其二, 科学化就是科学化我。科学化我就是说科学化要有自我内涵, 需要有科学理论指 
导、科学制度保障、科学方法支撑。科学理论指导也就是说理论本身要科学, 要真正能够解 释失误内在联系, 并具有彻底性、统一性。科学制度就是要在制度内容、体系、程序、环境 都要科学。科学方法的支撑说的就是具体问题具体分析, 根据不同时间环境和工作中心确定 不同的方式。

其三, 科学化是经得起实践检验。人民群众是历史的检验者, 这个检验是以人民为中心, 这个检验说是可以在实践中达到预期目的和在不同环境加以复制, 这个科学化还要经得起历 史检验。不是短期效应, 是可持续发展和经得起考验的。

党的建设科学化水平的提出是在现实基础上对历史经验的总结，因为我们的工作与现实 生活还存在差距, 认识和分析这些差距是提高科学化水平的基础。全面提高党的建设科学化 不是个人说了算, 不是英雄说了算, 是有一定的依据的, 实现中国梦的路还很长, 党面临的 赶考还没结束, 要 “考试合格”才能梦想成真。

\section{2. 为何在新时代要提高党的建设科学化水平?}

习近平总书记在党的十九大报告中提出了新时代党的建设总要求, 强调 “不断提高党的 建设质量, 把党建设成为始终走在时代前列、人民衣心拥护、勇于自我革命、经得起各种风 浪考验、朝气蓬勃的马克思主义执政党”, 总书记为什么提出要提高党的建设质量? 中国共 产党作为中国特色社会主义的本质和优势, 要走好走国道路, 发挥好特色, 打铁必须自身硬。 新时代对党的建设提出了新要求。

\section{1 以党的政治建设为统领}

习近平指出, 党的政治建设是党的根本性建设, 决定党的建设方向和效果。在党的各项 建设中, 党的政治建设处于统领地位。他指出, 党的政治建设的首要任务, 是保证全党服从 中央, 坚持党中央权威和集中统一领导。这既对新时代加强党的先进性和纯洁性建设具有重 大的现实指导意义, 又丰富了马克思主义执政党建设的理论宝库。党的政治建设要在严格和 规范党内政治生活、营造风清气正良好政治生态上下功夫。旗帜鲜明讲政治, 是马克思主义 政党的本质特征, 是保持党的政治生机和活力的重要法宝。以党的政治建设为统领, 能够发 挥纲举目张的作用。

\section{2 用新时代中国特色社会主义思想武装全党}

加强党的思想建设，必须用习近平新时代中国特色社会主义思想武装全党。这就是要用 马克思主义中国化的最新成果推动党的思想建设。具体来说, 就是要做好以下两个方面: 一 是抓好党性教育这个核心，解决好世界观、人生观、价值观这个 “总开关” 问题; 二是弘扬 马克思主义学风, 推进 “两学一做” 学习教育常态化制度化, 在全党开展以县处级以上领导 干部为重点的主题教育—— “不忘初心、牢记使命” , 从而推动全党更加自觉地为实现新时 代党的历史使命不懈奋斗。要以思想建党作为提高党的建设质量的支柱, 就必须以坚定理想 信念为核心主旨, 通过理论学习、党员教育的常态化、制度化, 确保一代代党员同志都能牢 记党的宗旨, 挺起共产党人的精神脊梁。

\section{3 加强新时代党的组织建设}

在组织建设上, 习近平重点强调两方面: 一方面要培养高素质专业化的干部队伍。高素 质是新时代对干部能力的要求, 而专业化是适应现代社会分工精细化的需要。在各部门、各 领域工作的党员干部和领导干部只有具备了相应的专业素养, 才能实现有效的驾驭和管理, 同时, 党的建设本身的专业化也需要具有专业素养的党务工作者。另一方面要继续加强党的 基层组织建设。党的基层组织是确保党的路线方针政策和决策部署贯彻落实的基础, 是党的 事业不断走向胜利的组织保障。 


\section{4 加强新时代党的作风建设}

党的作风是党的性质和宗旨的外在表现，直接体现党的形象，关系党的生死存亡。

持之以恒正风肃纪, 这表明未来我们党将继续推进常规性、制度性反腐, 真正做到把权 力关进制度的笼子。就具体工作而言, 一方面要坚持以上率下, 继续严格落实中央八项规定 精神, 继续整治 “四风” 问题; 另一方面要坚持惩前毞后、治病救人，抓早抓小、防微杜渐。 让党员、干部知敬畏、存戒惧、守底线。这是加强作风建设的一条新思路, 抓早抓小, 更有 利于保护党员干部。

\section{5 加强新时代党的纪律建设}

只有党的纪律和规矩真正树立起来，政治建党、思想建党和组织建党才具有监督机制, 党的作风才不会松松垮垮。党要承载起实现中华民族伟大复兴的使命, 其核心竞争力就是党 的纪律。习近平在十九大报告中, 纪律建党主要讲到了两方面, 一方面是夺取反腐败斗争的 压倒性胜利，这表明未来的反腐败斗争仍将保持高压态势，对于腐败分子仍将重拳出击。

另一方面健全党和国家监督体系。党的监督体系是党的建设的一项保障工程。习近平在 十九大报告中拓展了监督主体和监督渠道, 赋予了新的内容, 强调建立健全更加完善的党和 国家监督体系, 阐述这一体系的架构、布局和重点。增强党自我净化能力, 根本靠强化党的 自我监督和群众监督。这表明健全新时代的完整、严密的党和国家监督体系, 将为取得反腐 败斗争压倒性胜利提供有力支撑。

\section{6 全面增强执政本领}

习近平在十九大报告中特别强调要 “全面增强执政本领”，使我们党既要政治过硬，也 要本领高强。执政本领, 就是在执政活动中正确处理各种问题, 推进党的自身建设和党的事 业顺利发展的本领。他指出, 要增强学习本领、政治领导本领、改革创新本领、科学发展本 领、依法执政本领、群众工作本领、狠抓落实本领、驾驭风险本领。这八大执政本领的提出, 都是我们党在新时代肩负伟大历史使命、实现伟大目标所迫切需要的。

在新时代, 习近平提醒全党, 要全面增强执政本领。正因为我们党在每一个新时代开启 或重要历史转折点上, 都能够根据时代要求和实践需要, 未雨绸缪, 把增强本领作为党的建 设的重要要求, 所以, 我们党成功完成了每个历史时期的历史任务。新时代全面增强执政本 领, 必将使我们党更好地肩负起新时代的历史使命, 领导人民实现民族复兴的伟大梦想。

\section{3. 新时代提高党的建设科学化水平何为?}

新时代全面提高党的建设进入新征程，中国共产党是具有 “四个自信”、坚定“四个全 面”, 实践 “四个伟大”, 具有中国底气、中国风格, 中国特色的马克思主义政党。卓著成 就和历史经验告诉我们, “打铁还需自身硬”，党的建设在发展的路上不断完善。

\section{1 遵循规律, 扎实推进伟大工程建设}

有学者明确指出, “《古田会议决议》提出了 “使党员的思想和党内生活都政治化、科 学化” 的重大命题。” “党的十七届四中全会要求把 “提高党的建设科学化水平, 作为指导 实践的基本经验, 要求长期坚持, 并不断丰富发展。” ${ }^{[11]}$ 党和人民事业发展到什么阶段, 党 的建设就要推进到什么阶段。这是习近平总书记在庆祝中国共产党成立 95 周年大会上的讲话 揭示的加强党的建设基本规律。深刻认识、自觉遵循这一基本规律, 对于我们准确把握事业 发展新要求, 扎实推进全面从严治党, 具有重要意义。 ${ }^{[12]}$ 党的十八大以来, 习近平同志围绕 全面从严治党这个主题, 创造性地提出一系列新思想新观点新论断, 深刻回答了新的历史条 件下 “建设一个什么样的党、怎样建设党” 这一党的建设根本问题, 为坚持党的领导、推进 全面从严治党提供了根本遵循和科学指导。她们先后为继、一脉相成。 
习近平总书记在党的十九大报告中指出： “伟大斗争，伟大工程，伟大事业，伟大梦想， 紧密联系、相互贯通、相互作用, 其中起决定性作用的是党的建设新的伟大工程。这是一场 长期持续的斗争, 这是一场广泛参与全球竞争与合作的斗争, 这是一场全方位推进社会变革 的斗争, 这是一场和平有序的斗争, 这是一场没有硝烟却胜似硝烟的斗争, 这是一场以人民 为中心的斗争。它需要我们顺应人民群众对美好生活的向往, 我们离共同富裕的目标越来越 近，离中华民族伟大复兴的梦越来越近，离共产主义理想目标越来越近。

推进伟大工程, 要结合伟大斗争、伟大事业、伟大梦想的实践来进行, 确保党在世界形势深 刻变化的历史进程中始终走在时代前列, 在应对国内外各种风险和考验的历史进程中始终成 为全国人民的主心骨, 在坚持和发展中国特色社会主义的历史进程中始终成为坚强领导核心。

\section{2 抓住根本, 用习近平新时代中国特色社会主义思想武装全党}

第一项讲的是政治建设，第二项讲的就是思想建设。报告指出，“思想建设是党的基础 性建设。革命理想高于天。共产主义远大理想和中国特色社会主义共同理想, 是中国共产党 人的精神支柱和政治灵魂, 也是保持党的团结统一的思想基础。”人的所有行为来自于主观 认知的指导, 思想建设具有根本性、基础性。而且我们中国共产党又是一个大的党, 那这支 队伍的团结统一要有思想基础作为前提和保证。中国人实际上对这个规律总结得很清楚, 志 同才能够道合，这个 “志” 就是共产主义远大理想和中国特色社会主义共同理想。思想建设 达到标准, 整个党的建设实践工作才能够有保证。报告特别提出, “要把坚定理想信念作为 党的思想建设的首要任务, 教育引导全党牢记党的宗旨, 挺起共产党人的精神脊梁, 解决好 世界观、人生观、价值观这个 “总开关” 问题, 自觉做共产主义远大理想和中国特色社会主 义共同理想的坚定信仰者和忠实实践者”。

沧海横流显砥柱, 万山磅礴看主峰。习近平总书记强调, 中国共产党是世界上最大的政 党。大就要有大的样子。他号召全党永葆蓬勃朝气, 永远做人民公仆、时代先锋、民族脊梁。 作为有着 8900 多万名党员的全世界最大政党, 只要我们党把自身建设好、建设强, 确保党始 终同人民想在一起、干在一起, 勇于变革、勇于创新, 永不僵化、永不懈怠, 就一定能够团 结带领全国各族人民实现推进现代化建设、完成祖国统一、维护世界和平与促进共同发展三 大历史任务，走向中华民族伟大复兴的光明前景。

\section{3 筑牢国魂, 坚定党对一切的领导}

所谓国魂就是国家意识形态, 那么中国的国魂就是要走好中国特色社会主义道路。党的 领导是中国特色社会主义的本质和优势, 必须要坚持加强党的领导, 这是我们过去的表述。 党的十九大这样讲: “坚持加强党的全面领导”。“全面” 两个字至关重要。按照党的十九 大的定位, 党的建设中摆在首位的是政治建设。而政治建设的一系列要求, 比如: 坚决维护 党中央权威, 维护党中央的集中统一领导, 这是对整个国家、整个党的全面领导。全面讲的 是整体、全方位、全覆盖。这就是新的表述, 强调的是党的领导是全方位的、全覆盖的。既 然党对一切的领导都是在不断前进, 全面提高党的科学化水平建设也是不断进步的, 在党的 建设方面, 特别提出 “以党的政治建设为统领” 。这是党的十九大新的定位、新的表达。这 就更突出了党的建设主旨、定位、核心要素、核心方向。这是对新时代党的建设新的伟大工 程的重要规律的揭示。党的建设首先集中在政治建设上。

\section{4 围绕中心，履行新世纪新阶段新使命}

新时代新征程, 围绕着实现中华民族伟大复兴中国梦的中心任务, 全面建设社会主义现 代化强国需要提高党的建设科学化水平。时代在变化, 时代在发展, 实践在促使, 时代在要 求。新时代, 新要求, 全面推进党的建设科学化水平具有新内涵, 但是始终围绕着 “建设什 么样的党、如何建设党” 提出的一系列要求。面对党领导作用的加强, 面对党的十九大报告 对新时代党的建设以及党的建设的重点工作作了全局部署, 深化对党的建设规律性认识, 提 
出了新时代党的建设总要求和八个具体要求。

总要求意味着什么? 党的十九大为新时代党的建设新的伟大工程确立了总布局、总方向 和总布局。我们在实践中推进全面从严治党向纵深发展, 要在党的建设的发展和创新中向前 迈进, 都要遵循和贯彻总要求提出的标准和要求。

十九大报告提出的新时代党的建设总要求是：坚持和加强党的全面领导，坚持党要管党、 全面从严治党, 以加强党的长期执政能力建设、先进性和纯洁性建设为主线, 以党的政治建 设为统领, 以坚定理想信念宗旨为根基, 以调动全党积极性、主动性、创造性为着力点, 全 面推进党的政治建设、思想建设、组织建设、作风建设、纪律建设, 把制度建设贯穿其中, 深入推进反腐败斗争, 不断提高党的建设质量, 把党建设成为始终走在时代前列、人民衷心 拥护、勇于自我革命、经得起各种风浪考验、朝气蓬勃的马克思主义执政党。十九大对新时 代党的建设提出了完整的要求, 为我们在实践中如何进一步深化和推进党的建设提出了一个 完整的标准、方向和指南。这是一个完整的体系。

我们要特别注意的是什么? 在总要求里, 习近平同志对新时代党的建设的规律用总结一 般规律的方式提出了一些新的命题、新的概念。这些新命题新概念是对新时代党的建设新的 伟大工程规律的揭示和总结。按照总要求来推进党的建设, 就能够保证我们按照新时代党的 建设的基本规律、基本要求来工作。

\section{5 注重实效, 全面从严治党向纵深发展}

全面从严治党如何治? 习近平同志讲得非常清楚，就是制度治党、依规治党。制度建设 至关重要，而其特殊性就在于贯穿和渗透融汇融合在党的建设的各个方面。“全面推进党的 政治建设、思想建设、组织建设、作风建设、纪律建设，把制度建设贯穿其中”，这个新概 括反映了新时代党的建设新的伟大工程的重要规律。

“深入推进反腐败斗争，不断提高党的建设质量”。而 “不断提高党的建设质量”也是 党的十九大在党的领导、党的建设方面的新概念、新表述, 也是新时代党的建设新的伟大工 程的规律和本质。党的建设固然能够用一些数量的指标、数据来标识, 但今天党的建设进入 到了新时代, 新时代就要有新时代的特征和规律, 就提出党的建设自身也有质量的问题。党 的十九大提出 “不断提高党的建设质量” ，就是从更深层次对推进党的建设提出了更高的标 准。我们不能满足于过去的一些数量性、指标性数据, 还应该在质量方面做实, 踏踏实实地 把质量提升上去。这就是党的建设的新标准、新要求。

\section{4. 结语}

总的来说, 十九大对于推进新时代党的建设的总要求, 全方位地概述了新时代党的建设 的重要规律, 对我们党的建设的探索和实践提出了新标准和新要求。这就要求我们要认真学 习把握党的十九大提出的这些标准和要求, 真正把握新时代党的建设的新特点新规律。所以, 党的建设总要求实际上是提出党的建设的新任务。

总之, 中国共产党作为中国特色社会主义的动车头, 要向高速发展, 必须走好每一步, 不仅提升速度, 关键在于质量的提高, 党的建设科学化是对规律的把握, 是对本质诠释, 当 然能够把党建设的越来越好。

\section{致谢}

本文受广西高校科学技术研究项目 (KY2015LX594) 资助。 


\section{References}

[1] Central Compilation and Translation Bureau. Marx and Engels's Anthology (vol.4). [M]. Beijing: People's Publishing House. 1995.395.

[2] Central Compilation and Translation Bureau. Lenin's Complete Works (vol.6). [M]. Beijing: People's Publishing House. 1986.

[3] Mao Zedong. Mao Zedong Writings.[M].Beijing: People's Publishing House, 1986.

[4] Wang Changjiang. Improving the Scientific Level of Party Construction.[M]. Beijing: Press OF the party School of the Central Committee.2010.

[5] Jiang Zemin. Jiang Zemin Anthology (vol.1).[M]. Beijing: People's Publishing House. 2006.

[6] Deng Xiaoping. Deng Xiaoping Anthology (vol.2).[M]. Beijing: People's Publishing House. 1994.

[7] Jiang Zemin. Jiang Zemin Anthology (vol.2).[M]. Beijing: People's Publishing House. 2006.

[8] Jiang Zemin. Jiang Zemin Anthology (vol.3).[M]. Beijing: People's Publishing House. 2006.

[9] The Book Group. Chinese Communist Party's Education Manual (vol.7). [M]. Beijing: People's Publishing House.2016.

[10]Deng Xiaoping. Deng Xiaoping Theory of The Party [M]. Beijing: People's Publishing House. 1990.

[11]Yuan Zhongxin. Follow the Law to Promote the Scientific Development of the Military Party [J]. Journal of Xi 'an Politics Institute,2010(23):51.

[12] Tian Zhe. In Accordance with the Party's Basic Law of Building a Comprehensive and Strict Discipline -- Learning the Important Speech of General Secretary Xi Jinping [N]. China Discipline Inspection Report,2016-7-6(5). 